\title{
MODAL TESTING OF AN ISOLATED OVERPASS BRIDGE IN ITS CONSTRUCTION STAGES
}

\author{
Fuat ARAS* \\ Istanbul Medeniyet University, Ünalan Kampüsü, H Blok, No:25, Üsküdar 34700, Istanbul, Turkey
}

Received 21 August 2017; accepted 19 December 2017

\begin{abstract}
This study presents the application of ambient vibration survey based dynamic testing on an isolated, precast and pre-stressed overpass bridge during and after its construction. In the studied three-bay bridge, the girders are located on the elastomeric bearings carried by two abutments and two internal piers. The first modal testing is performed after the placement of the girders on the elastomeric bearings and dynamic properties of the uncompleted bridge are determined. After the completion of all construction works and the opening of the overpass to human traffic, the modal testing is repeated to obtain the dynamic properties of the final structure. The dynamic properties obtained in both analyses are used to interpret the effects of the performed works between two modal testing. Moreover, the structural behaviour of isolated, precast and pre-stressed bridges is evaluated in detail.
\end{abstract}

Keywords: construction stages, dynamic identification, modal testing, pedestrian overpass.

\section{Introduction}

As a full-scale testing method, Ambient Vibration Survey (AVS) is an easy and practical way of identifying the dynamic properties of existing structures. It is specifically used to correct and tune the numerical models of the existing structures (Benedettini \& Gentile, 2011; Chan, Law, \& Yung, 1998; Lin, Zhang, \& Guo, 2009; Osmancikli, Bayraktar, Turker, Ucak, \& Mosallam, 2015; Sanayei, Khaloo, Gül, \& Eaatbas, 2015; Ubertini, Gentile, \& Materazzi, 2013; Ząrate \& Caicedo, 2008). Besides, its applications in different times and conditions to existing structures enable scientists and engineers to interpret the effects of different variables on the structural behaviour (Ko \& Ni, 2005; Soyöz et al., 2013; Paeglite, Smirnovs \& Paeglitis, 2017). Therefore, AVS is categorized as a frequently employed and well-known technique for dynamic testing of existing structures.

The use of isolated, precast and pre-stressed structures is increasing, because of their easy installation and high earthquake performance. However, the number of full scale tests on these bridges is low, but the recent studies are promising to reveal their behaviour. Altunışık, Bayraktar, Sevim, and Ateş (2011) applied AVS to isolated Gülburnu Bridge and used the obtained dynamic properties to tune the finite element model of the bridge for its seismic evaluation. They emphasized the capability of modal testing to extract the important modes of the isolated bridges. Bedon and Morassi (2014) applied harmonically forced vibration tests on a two-span post-tensioned reinforced concrete bridge with deck supported on six elastomeric isolators. They proposed an identification procedure, based on the experimental data and analytical models to estimate the stiffness of the isolation devices and, ultimately, to determine an accurate numerical model of the bridge. Later on, Chisari, Bedon, and Amadio (2015) have applied a different identification procedure based on the general algorithm to the same bridge.

In this study, the modal testing is applied to an isolated, precast, pre-stressed reinforced concrete overpass in Istanbul during and after its construction. The first testing is performed when the bridge is under construction, specifically, when the prefabricated beams are placed on the elastomeric bearings. Thereby dynamic properties of the uncompleted bridge are revealed. After the completion of all construction works, such as the cast-in-place reinforced concrete slab through the bridge, installation of the side-precast panels, stair and elevator systems, the bridge was opened to the human traffic and the second modal testing is performed for the identification of structural behaviour of the completed structure. The results of two AVSs are used to evaluate the effects of the performed

*Corresponding author. E-mail: fuat.aras@medeniyet.edu.tr 
construction works between two testing as the first aim of this study. Secondly, the general dynamic behaviour of isolated, precast and pre-stressed bridge is determined. Before presenting the details of the modal testing, the studied bridge is introduced in the next heading.

\section{Studied bridge}

The studied bridge is known as Istanbul Medeniyet University pedestrian overpass and is constructed within the Istanbul Strait Road Tunnel Crossing Project. It connects two campuses of the university and many people use it to cross the main motorway D100. Figure 1 shows the aerial view of the bridge with its neighbourhood.

The structural system of the bridge contains two reinforced concrete abutments, two mid piers, elastomeric bearings, precast and pre-stressed reinforced concrete girders, reinforced concrete slab and steel stairs. Two elevators with steel frame systems also join the bridge abutments from two sides. Caps on the abutments and piers were designed to carry the girders. The abutments also support the steel stair systems.

The bridge crosses 69.2 meter via three bays with the span lengths of $L_{1}=32.3 \mathrm{~m} ., L_{2}=22.1 \mathrm{~m}$., $L_{3}=12.8 \mathrm{~m}$. The width of the bridge is $5.2 \mathrm{~m}$ and two different girder crosssections are used through the bays. $L_{1}$ and $L_{2}$ bays are crossed by four precast pre-stressed girders, which height is $1200 \mathrm{~mm}$ and top flange width is $1275 \mathrm{~mm}$, while $L_{3}$ is crossed by six precast girders, which height is $900 \mathrm{~mm}$ and top flange width is $800 \mathrm{~mm}$. Figure 2 shows the structural system details of the studied bridge.

The C35 concrete class is used for all cast-in-place concrete members while $\mathrm{C} 40$ is preferred for precast and prestressed girders. $\mathrm{S} 420$ steel grade is used for all reinforcement. For the pre-stressing strands, $1862 \mathrm{MPa}(270 \mathrm{ksi})$ grade strand is used with $1.5 \mathrm{~cm}$ (0.6 inches) diameter. 21 strands are used for pre-stressing $L_{1}$ girders, while 8 strands are used for $L_{2}$ girders. No pre-stressing is applied to $L_{3}$ girders (Oruç, Sarıkaya, \& Küçük, 2016).

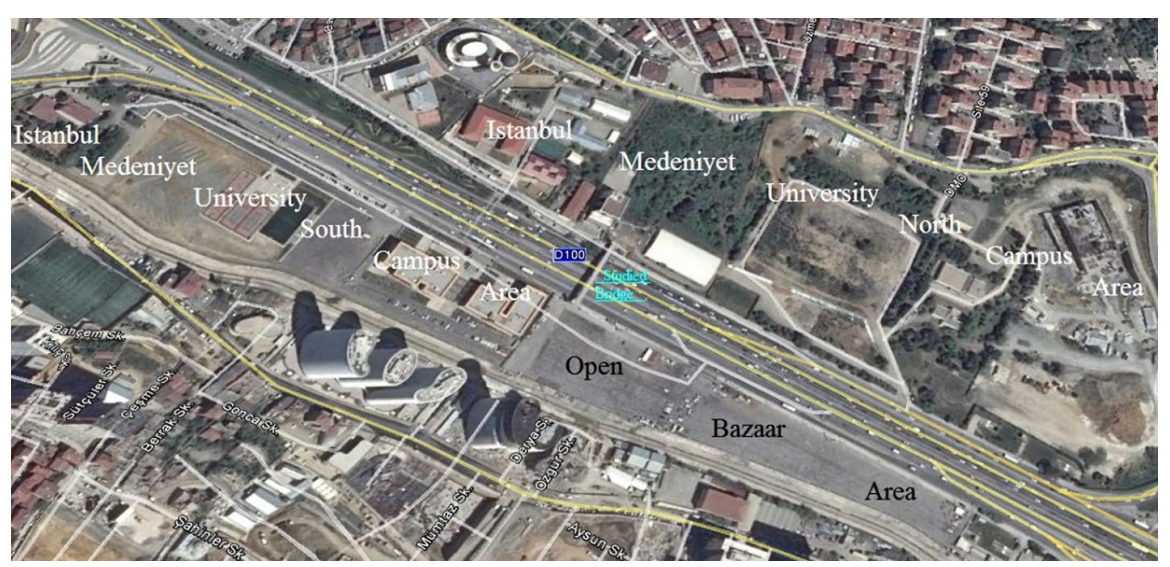

Figure 1. Location of the studied bridge

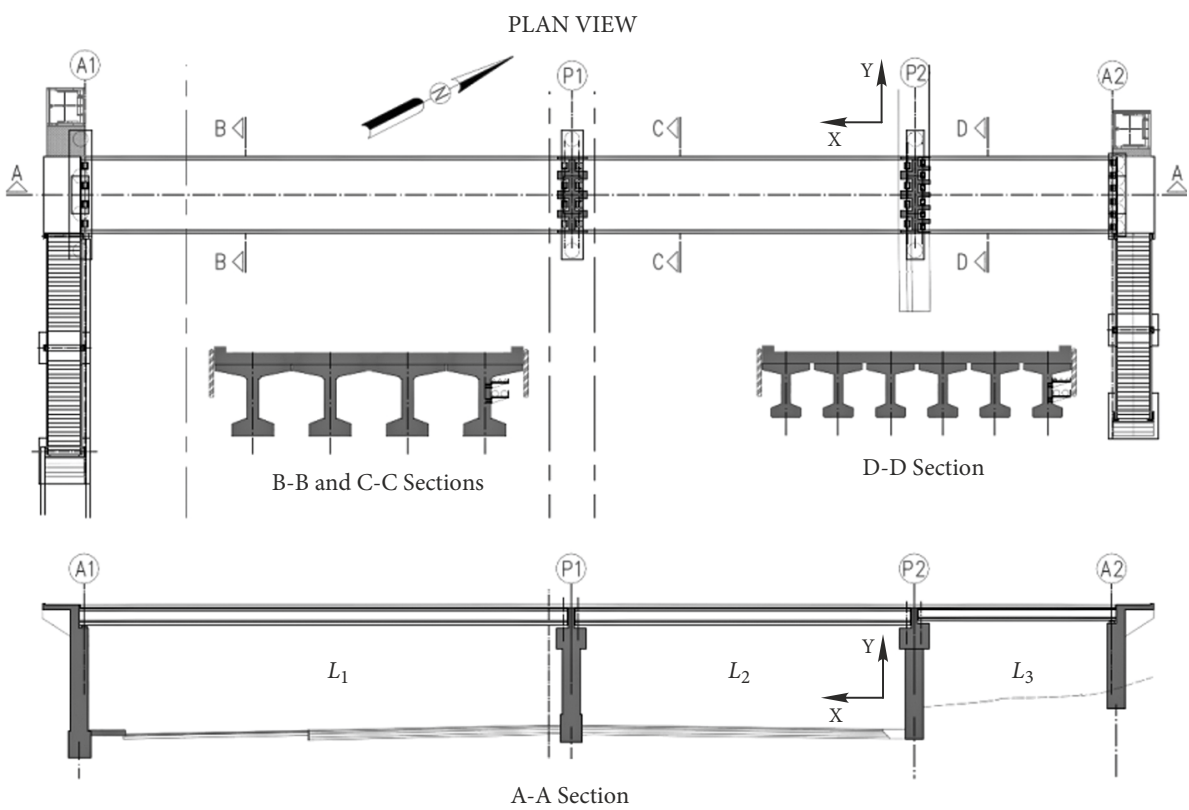

Figure 2. Structural system of the studied bridge (Oruç et al., 2016) 
The girders at three bays are located on the elastomeric bearings. Elastomers are usually used to form a separation line between the superstructure, i.e. the part of the structure over the elastomeric devices, and substructure, i.e. other part remains under the separation line (Aras \& Altay, 2015). The stiffness of the bearings is expected to dominate the dynamic behaviour of the superstructure and provides an elongated period set for the reduction of the seismic forces. As the substructure, abutments, and piers stay under the elastomers and transfer the loads to the ground by pile systems.

\section{Modal testing of the bridge during its construction}

The first modal testing was performed after the prefabricated girders were located on the caps of abutments and piers via elastomeric bearings. Figure 3 shows the studied bridge when the first modal testing was applied. As it is seen, the reinforced concrete slab has not been formed yet and there are wide gaps between the girders and the supports.

Three Kinemetrics, TSA-SMA accelerometers, with three sensors were used for data collection. The linear acceleration range of each sensor is $\pm 4 \mathrm{~g}$. Each accelerometer has its own data storage unit and works separately without a mutual data acquisition system. The required synchronization for the dynamic identification is provided by GPS (Global Positioning System) antenna. The acceleration records gathered by three accelerometers at the same time are analysed for mode extraction.

For the purpose of dynamic identification in the studied bridge, three sets of measurements are taken, since the modal degree of freedoms is more than the number accelerometers. In each set, one of the accelerometers is used as a reference sensor to relate the measurements taken at different times. The reference accelerometer is located on Pier 1 (P1), supporting $L_{1}$ and $L_{2}$ girders in this study. In the first set, other accelerometers are located on the Abutment 1 (A1) and mid-span of $L_{1}$. In the second set, three accelerometers are on P1, Pier 2 (P2) and mid-span of $L_{2}$. Finally, at the last set, they are on P1, Abutment 2 (A2) and midspan of $L_{3}$. Thereby, seven points (four vertical supports and three mid-spans of girders) are accounted with their three directions ( $X, Y$ and $Z$ ). These three-dimensional acceleration records, taken from seven points through the bridge are enough to obtain the mode shapes and modal frequencies of the studied bridge. Figure 4 summarizes the performed set of measurements on the studied bridge.

The modal parameter estimation of a structural system based on its vibration response is very important and many signal processing techniques have been developed and validated. These techniques are ranging from frequency domain algorithms based on the Fourier transform,

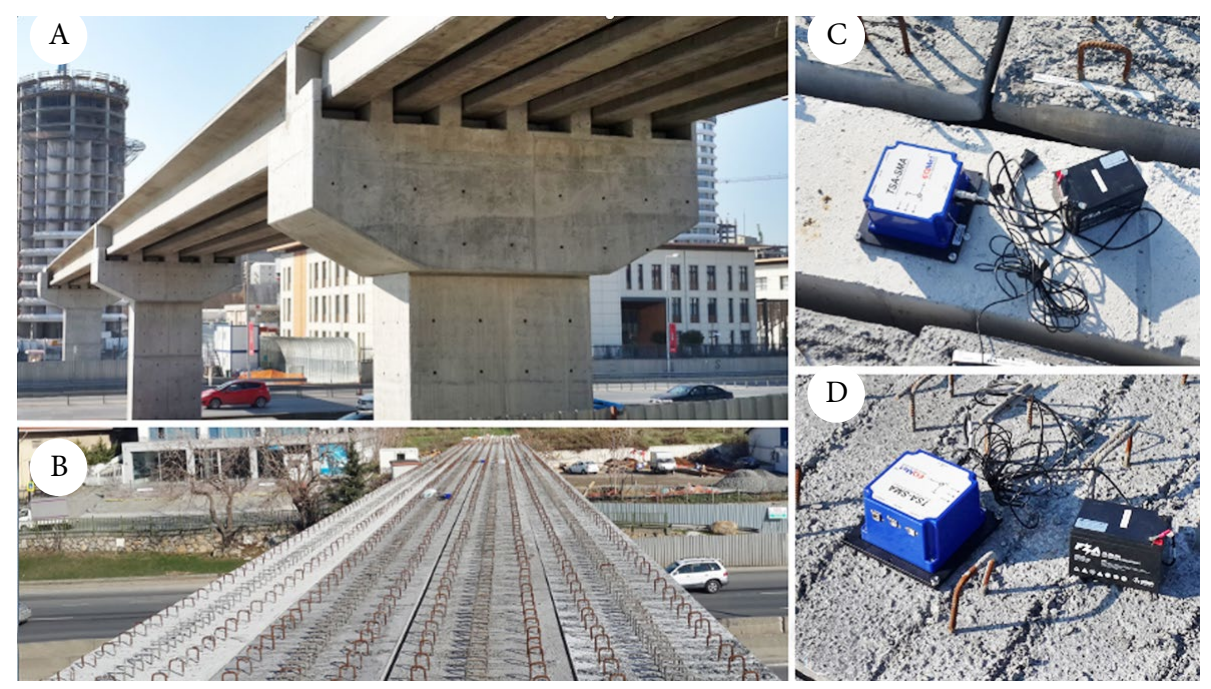

Figure 3. Modal testing on 23.01.2017 (A, B: studied bridge, C: accelerometer on a pier, D: accelerometer on mid-span)

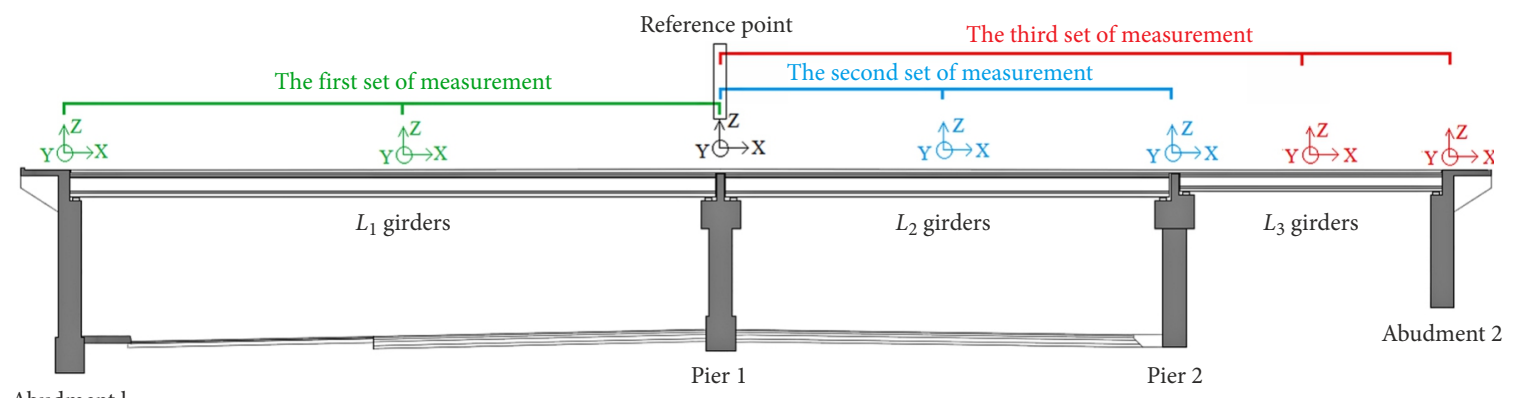

Figure 4. Application of modal testing with three accelerometers 
such as peak pick (PP) and frequency domain decomposition (FDD), to time domain algorithms, such as the Eigensystem realization algorithms (ERA) and the stochastic system identification (SSI) (Min \& Sun, 2013; Peeters \& DeRoeck, 2001). The frequency domain methods are the most practical methods to apply existing civil structures (Michel, Gueguen, \& Bard, 2008). For the studied bridge, the selection of appropriate modal identification technique in the frequency domain is important, due to elastomeric bearings, that are expected to create an isolation line and make the superstructure to have different dynamic properties from substructure. The selected system identification method should also reveal the dominant frequencies of the records taken from different locations at the structure as PP does. Thereby, dynamic properties of substructures and superstructure can be interpreted. If the FDD is used, the records of superstructure and substructure are evaluated together and the dominant frequencies were determined for the all structure. The distinction between the modal properties of the superstructure and substructure is only possible with a detailed evaluation of mode shapes on determined dominant frequencies. In that respect, PP is more practical and straightforward for the modal identification of the studied structure and preferred in this study.

The recorded vibrations are analysed with Matlab computer program (2012). No filtering is applied to the data and modal identification is performed generally between $0 \mathrm{~Hz}$ and $10 \mathrm{~Hz}$. This range is considered adequate for the identification of the studied structure. Frequency domain presentation of the records validated the dominant frequencies and their power densities are used to extract the modal displacements. The modal displacement of each degree of freedom at a specific frequency is proportional to the square root of the power spectral density. Figure 5 displays the frequency domain presentation of the signals for the first set of measurements in $X, Y$ and $Z$ directions. It is seen that, in the $X$ direction, the $L_{1}$ girders oscillate with a frequency of $1.34 \mathrm{~Hz}$ on the elastomers. Abutment 1 and P1 are in rest in this dynamic mode. At $2.73 \mathrm{~Hz}, \mathrm{~A} 1$, $L_{1}$ girders and Pier 1 form a dynamic mode in $\mathrm{X}$ direction. Along with $Y$ direction, the dominant frequency of A1 and P1 is $1.32 \mathrm{~Hz}$, while that of $L_{1}$ girders is $1.34 \mathrm{~Hz}$. The difference between the magnitudes of PSD (Power Spectral Density) of the girder signals and those of A1 or P1 indicates that, the dynamic mode formed by the movement of girders is clearer than the mode of supports. Finally, the frequency domain presentations along with $Z$ direction reveal the oscillation of the $L_{1}$ girder beams with a single frequency of $2.76 \mathrm{~Hz}$.

Figure 6 displays the frequency domain presentation of the signals for the second set of measurements performed for the dynamic identification of $L_{2}$ span in $X, Y$ and $Z$ directions. Along with $X$ direction, $2.73 \mathrm{~Hz}$ mutual dominant frequency takes attention at the first glance, proving the participation of the second bay into the dynamic mode. Unlike the first bay, the independent movement of the girders on the bearing is not observed. In $Y$ direction, the dominant frequencies are formed between $1.32 \mathrm{~Hz}$ and $3.01 \mathrm{~Hz}$ for the girders while $2.17 \mathrm{~Hz}$ was seen for P2. Vertical mode of the second bay girders is identified by a single frequency of $6.19 \mathrm{~Hz}$.

Figure 7 displays the frequency domain presentation of the signals for the third set of measurements performed to include $L_{3}$ girders and A2 in the modal testing. Along with $X$ direction $2.73 \mathrm{~Hz}$ mutual frequency is still notable, but it loses its density on $L_{3}$ and A2. However, two dominant frequencies, i.e., 4.28 and 5.87, increased their density for these locations. These frequencies were also notable in Figure 5 and Figure 6 with lower densities than those of $2.73 \mathrm{~Hz}$. Along with $Y$ direction, the main dominant fre-
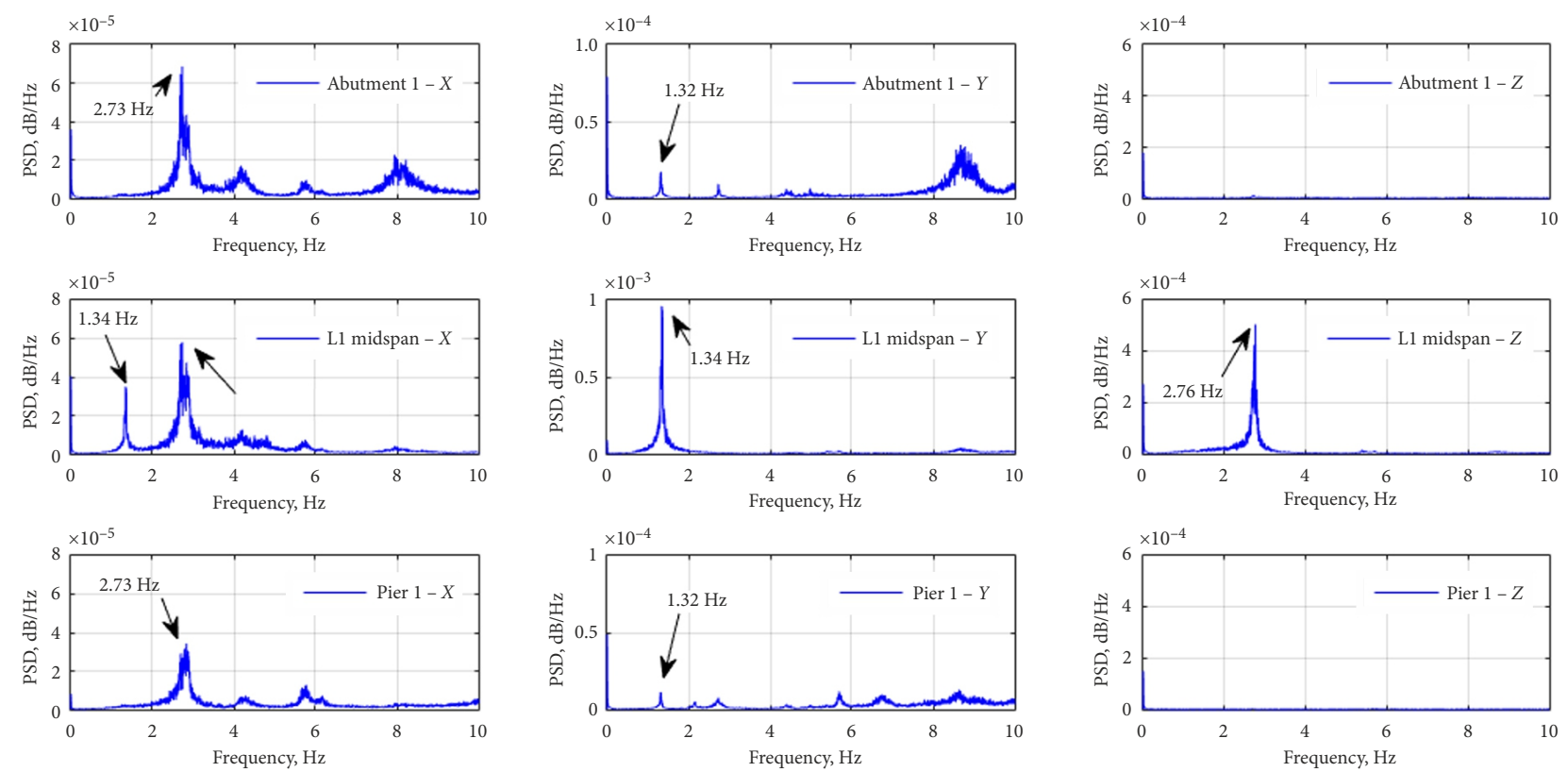

Figure 5. Frequency domain presentation of the signals for the first set of measurements in the first Ambient Vibration Survey 

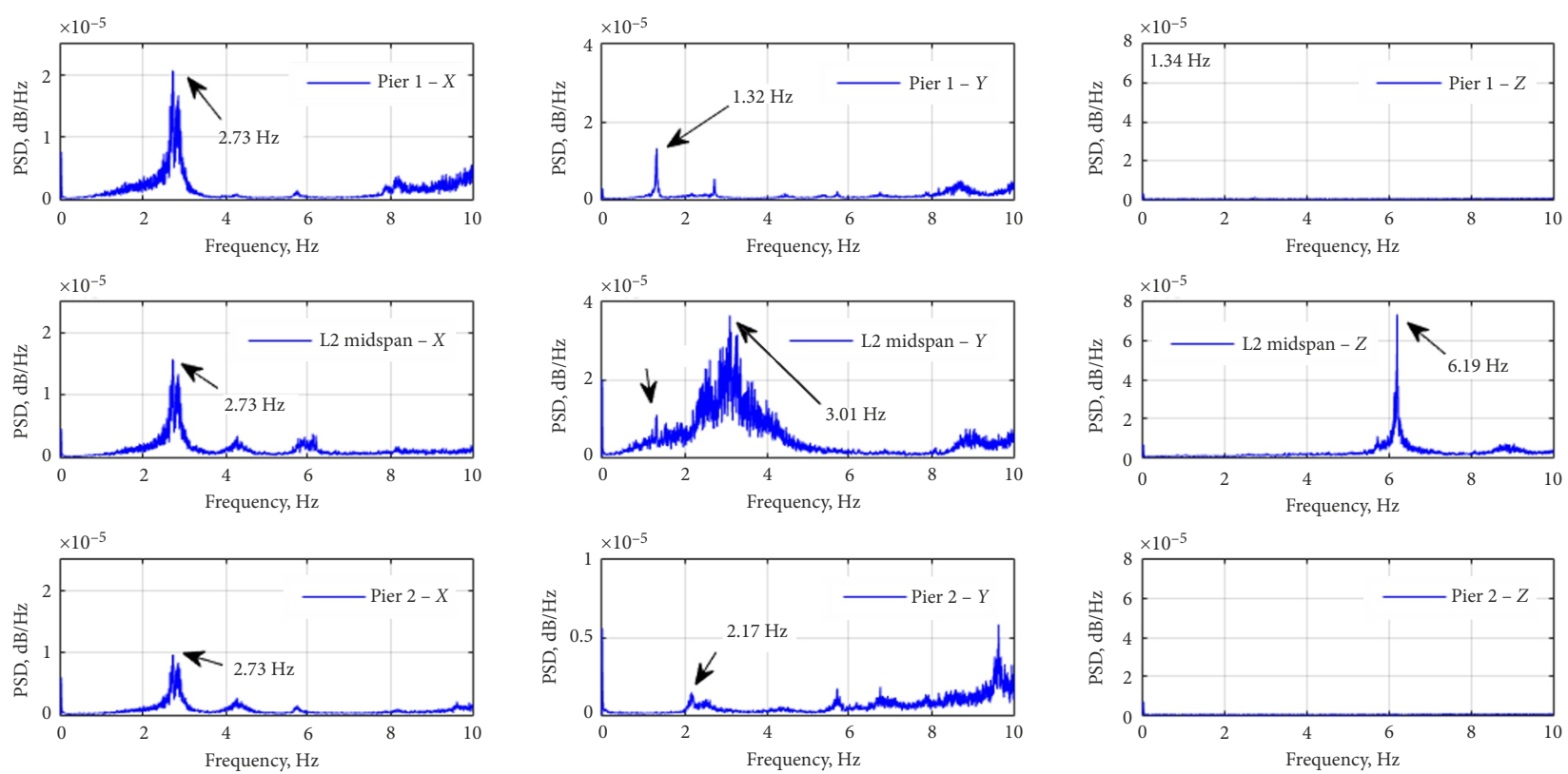

Figure 6. Frequency domain presentation of the signals for the second set of measurements in the first Ambient Vibration Survey
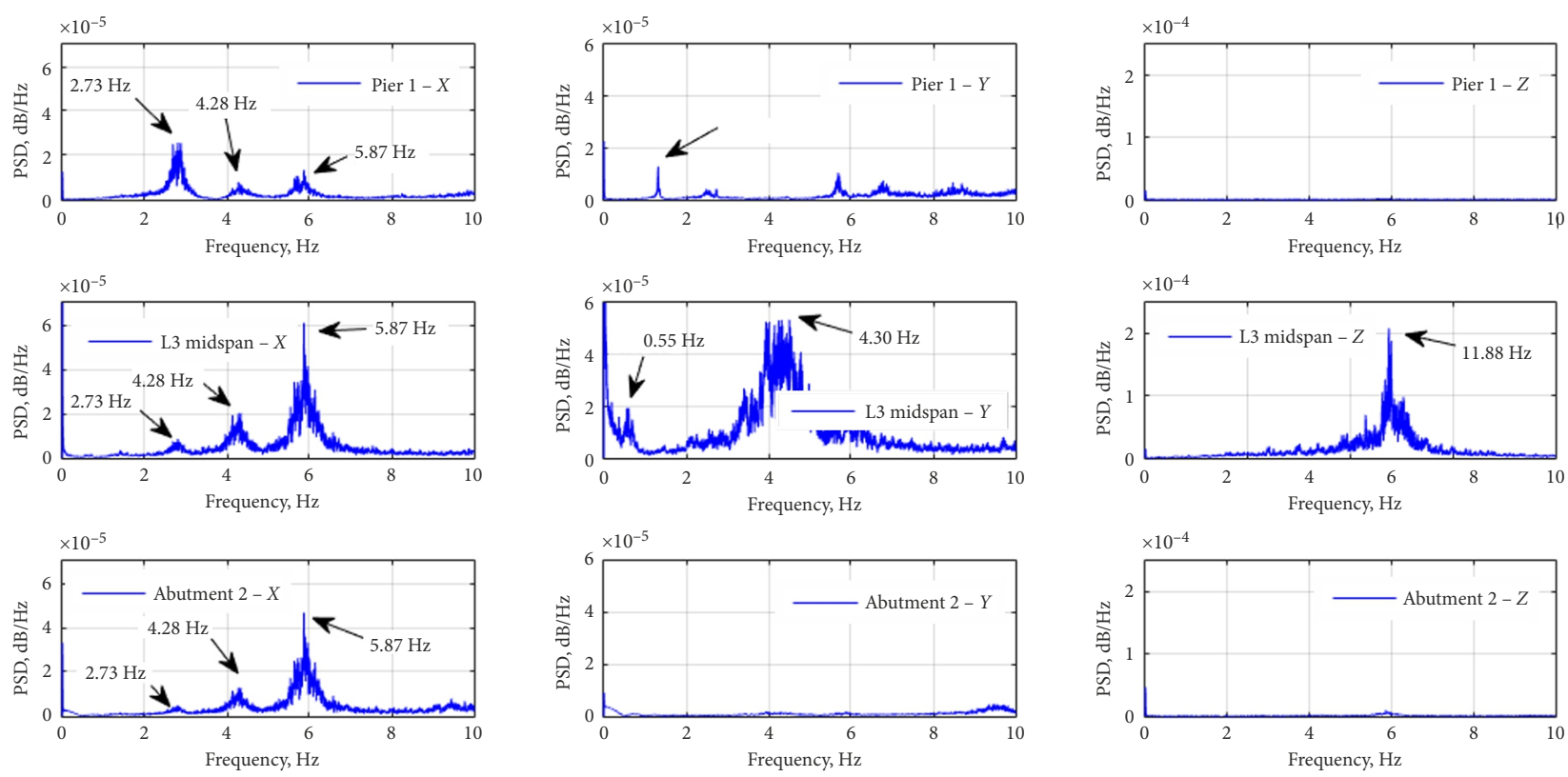

Figure 7. Frequency domain presentation of the signals for the third set of measurements in the first Ambient Vibration Survey

quency is $4.3 \mathrm{~Hz}$ for the girders. The dominant frequency for A2 is not determined. Finally, for the vertical mode of $L_{3}$, the frequency is determined as $11.88 \mathrm{~Hz}$.

As the result of the modal testing, the mode shapes of the studied structure are drawn with the explained frequency domain representations. Modal displacement in each dominant frequency is computed as the square root of the power density of the signals (Inman, 2013). Here, the reference measurement, seen in Figures 5-7, is used to relate the modal displacement values of different sets. As the last step, the obtained mode shapes are normalized to have the maximum modal displacement to be unity. In these respects, the obtained mode shapes are presented in Figures 8-10 for $X, Y$ and $Z$ directions, respectively.

\section{Modal testing of the completed bridge}

Second modal testing of the bridge was performed when it was already under service. After the application of the first modal testing, the steel stairs of the bridge were formed, the cast-in-place reinforced concrete slab with a thickness of $20 \mathrm{~cm}$ was added, the precast sides and parapets were installed, and the elevators with steel casings were completed. Since it was under service, people were crossing it during the measurements, but the elevators were not under service. For the test, a rare day was preferred and the rate of the traffic was determined as 2 people/minute on the bridge. The accelerometers were located on the west side of the span, unlike the first measurement, in which 

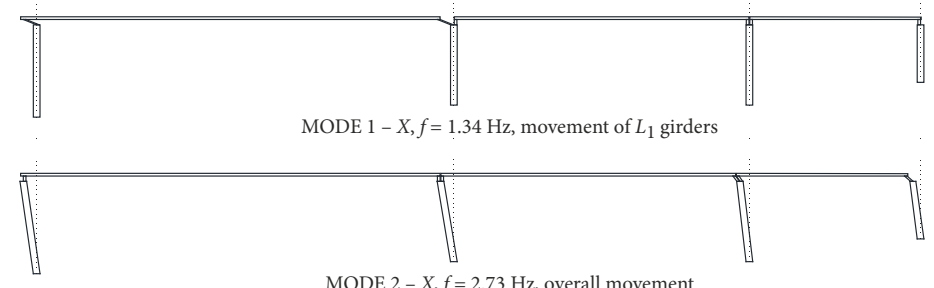

MODE $2-X, f=2.73 \mathrm{~Hz}$, overall movement

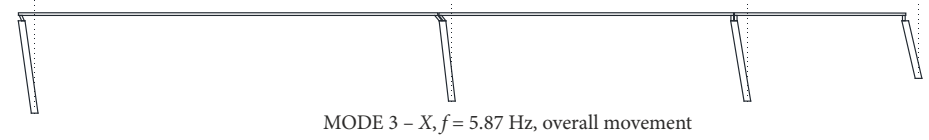

Figure 8. Obtained mode shapes in $X$ direction in the first Ambient Vibration Survey

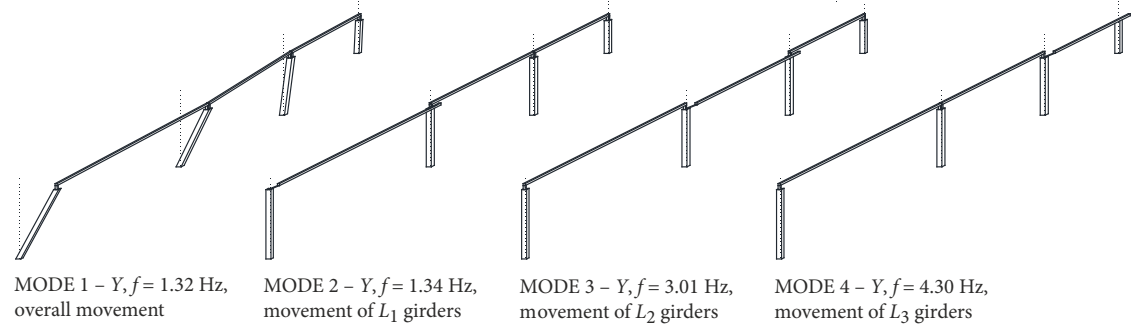

Figure 9. Obtained mode shapes in $Y$ direction in the first Ambient Vibration Survey
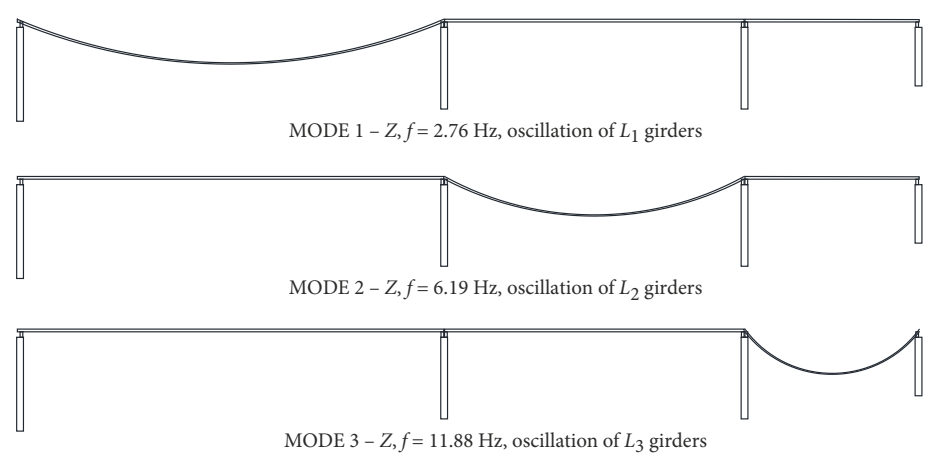

Figure 10. Obtained mode shapes in $Z$ direction in the first Ambient Vibration Survey

the middle regions were preferred. Figure 11 shows the bridge during the second AVS.

The same configuration and analysis details as it was in the first AVS are applied for the second AVS. Figure 12 shows the frequency domain presentation of the first set of measurements taken from the completed bridge. Along with $X$ direction, the mutual frequencies, i.e., $3.00 \mathrm{~Hz}$ and $3.45 \mathrm{~Hz}$, take attention, proving the overall behaviour of the system. Another mutual frequency is seen beyond $6 \mathrm{~Hz}$. The same interpretation is valid for the dynamic behaviour along with Y direction. $3.7 \mathrm{~Hz}, 4.78 \mathrm{~Hz}$, and $5.6 \mathrm{~Hz}$ are the mutual frequencies for $\mathrm{A} 1$, girders and $\mathrm{P} 1$. Additional dominant frequencies are also noted beyond $8 \mathrm{~Hz}$ in $X$ and $Y$ direction, but they are not discussed in detail since they represent higher modes, which are unimportant and difficult to interpret. For the vertical mode in $Z$ direction, two dominant frequencies are noted as $2.99 \mathrm{~Hz}$ and $4.78 \mathrm{~Hz}$ for the $L_{1}$ span.
Figure 13 shows the frequency representations of the signals taken from P1, $L_{2}$ mid-span and $\mathrm{P} 2$ as the second set of measurement. The general shape of the spectrums is similar with respect to different locations in $X$ and $Y$ directions. This similarity indicates that, $\mathrm{P} 1, L_{2}$ mid-span and P2 moves altogether in these modes. The dominant frequencies in the $X$ direction are determined as $3.00 \mathrm{~Hz}$ and 3. $45 \mathrm{~Hz}$, while they are $3.7 \mathrm{~Hz}, 4.78 \mathrm{~Hz}$ and $5.6 \mathrm{~Hz}$ in the $Y$ direction. In $Z$ direction two dominant frequencies are determined as $6.30 \mathrm{~Hz}$ and $8.30 \mathrm{~Hz}$ for the modes representing the oscillation of the girders.

The frequency domain representations of signals taken on the third measurement are shown in Figure 14. The overall modes along with $X$ direction are confirmed. In $Y$ direction $L_{3}$ girders and $\mathrm{A} 2$ are inactive in the modes with $3.7 \mathrm{~Hz}, 4.78 \mathrm{~Hz}$ and $5.6 \mathrm{~Hz}$ modal frequencies. The dynamic behaviour of these parts is seen in higher modes on $9.18 \mathrm{~Hz}$, on which $\mathrm{A} 1, L_{1}$ girders, $\mathrm{P} 1$ and $L_{2}$ girders are 


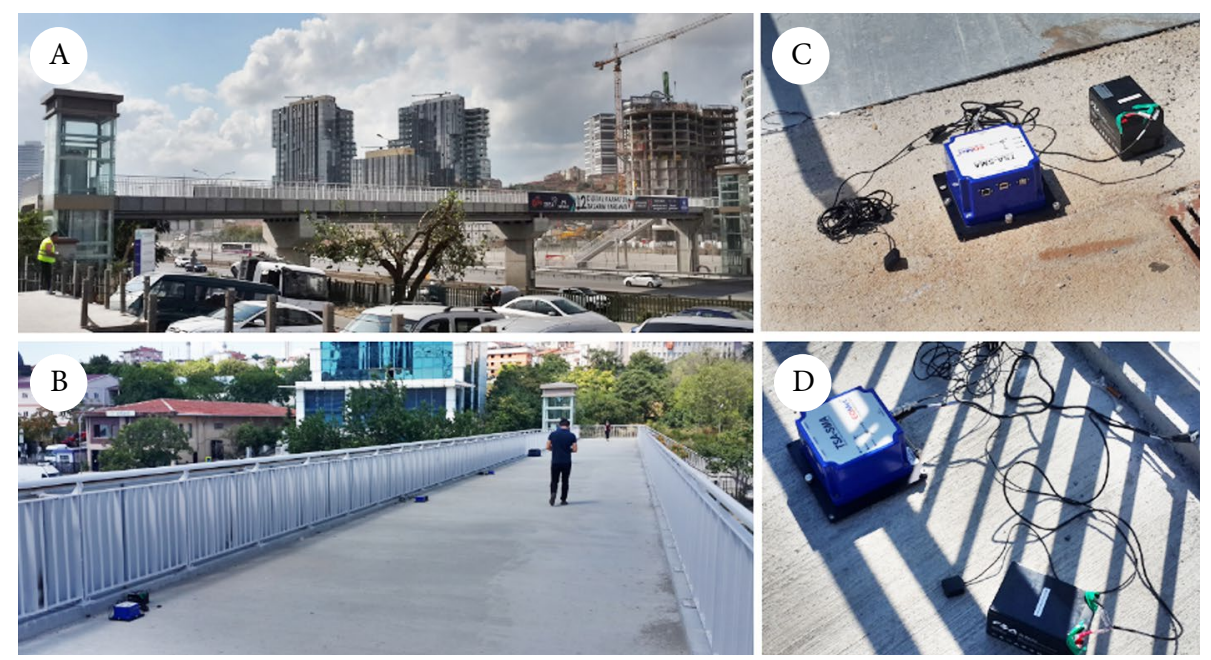

Figure 11. Modal testing (A, B: studied bridge, C: accelerometer on a pier, D: accelerometer on mid-span)
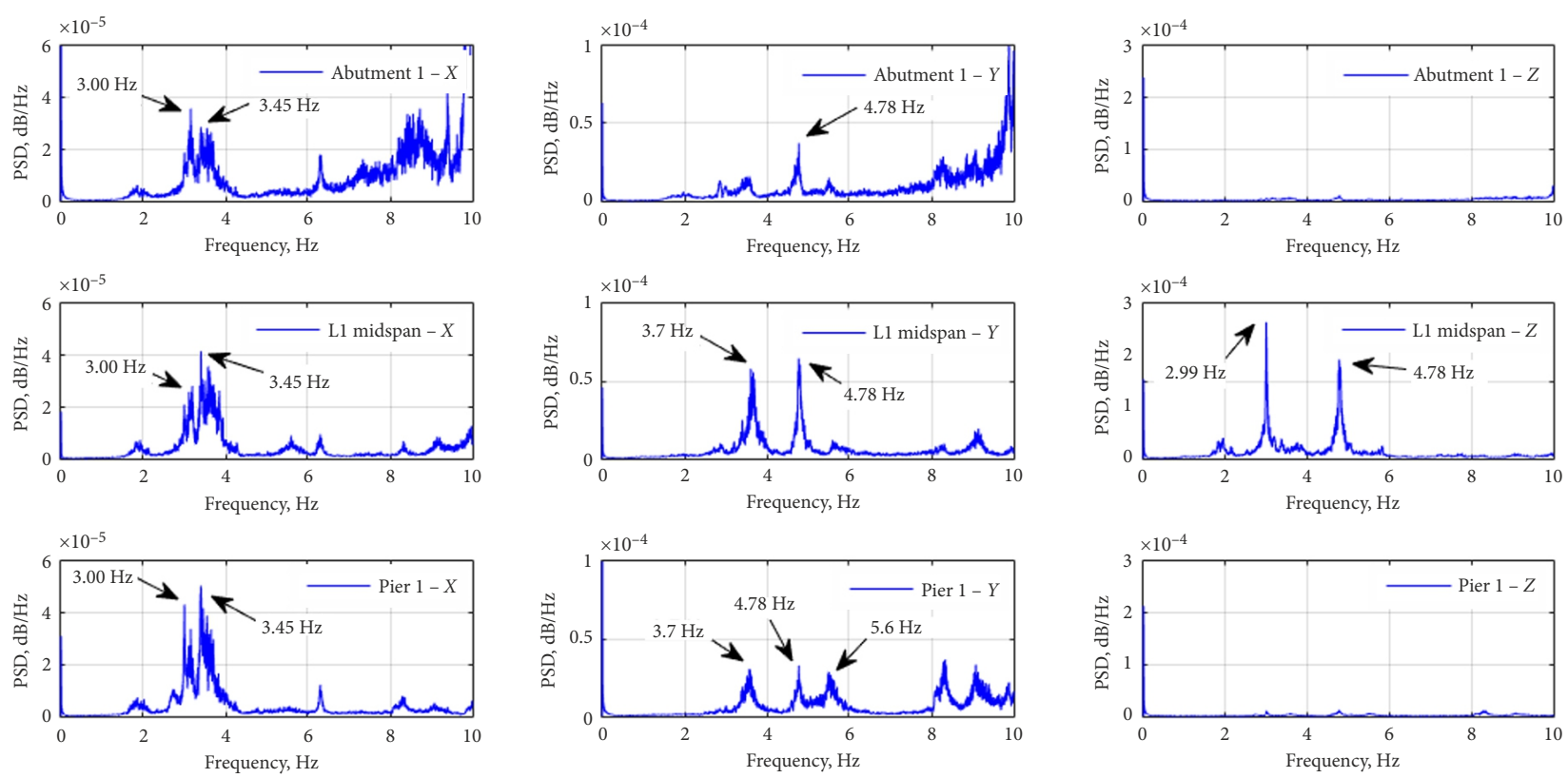

Figure 12. Frequency domain presentation of the signals for the first set of measurements in the second Ambient Vibration Survey

active. Finally, the vertical movements of the girder beams are detected on the frequencies of $12.38 \mathrm{~Hz}$ and $13.38 \mathrm{~Hz}$.

The reference measurements taken from P1 enable to draw the mode shapes of the bridge by computing the modal displacement as the square root of the PSD at a specific frequency. The obtained mode shapes are illustrated in Figures 15-17.

\section{Structural behaviour of the bridge and the effects of the performed works between two stages}

Direct comparison of the modal characteristics of the studied bridge obtained in two modal testing reveals the effects of the construction works performed in the time interval passed between two stages. Besides, the evaluation of the obtained mode shapes reveals the behaviour of isolated bridges and shows how the expected behaviour is accomplished.

\subsection{Structural behaviour of the bridge during its construction}

The mode shapes of the structure are presented in Figures 8-10 after the first AVS. In this stage, the girders were located on the elastomers standing on the abutments and piers. Since there are no connections between the supports and the beams except the elastomers, girders on $L_{1}, L_{2}$, and $L_{3}$ are disconnected from each other. In this respect, generally, the girders form their own dynamic modes.

Indeed, the mode shapes prove that, $L_{1}, L_{2}$, and $L_{3}$ have their own modes in the $Y$ direction, while in $X$ direction only $L_{1}$ has its own mode. In this study, $X$ is the span direction of the bridge and only $L_{1}$ girders have their own mode in this direction. The independent mode of the $L_{2}$ and $L_{3}$ were not seen due to the possibility of restrains in respective displacements developed in the structure. 

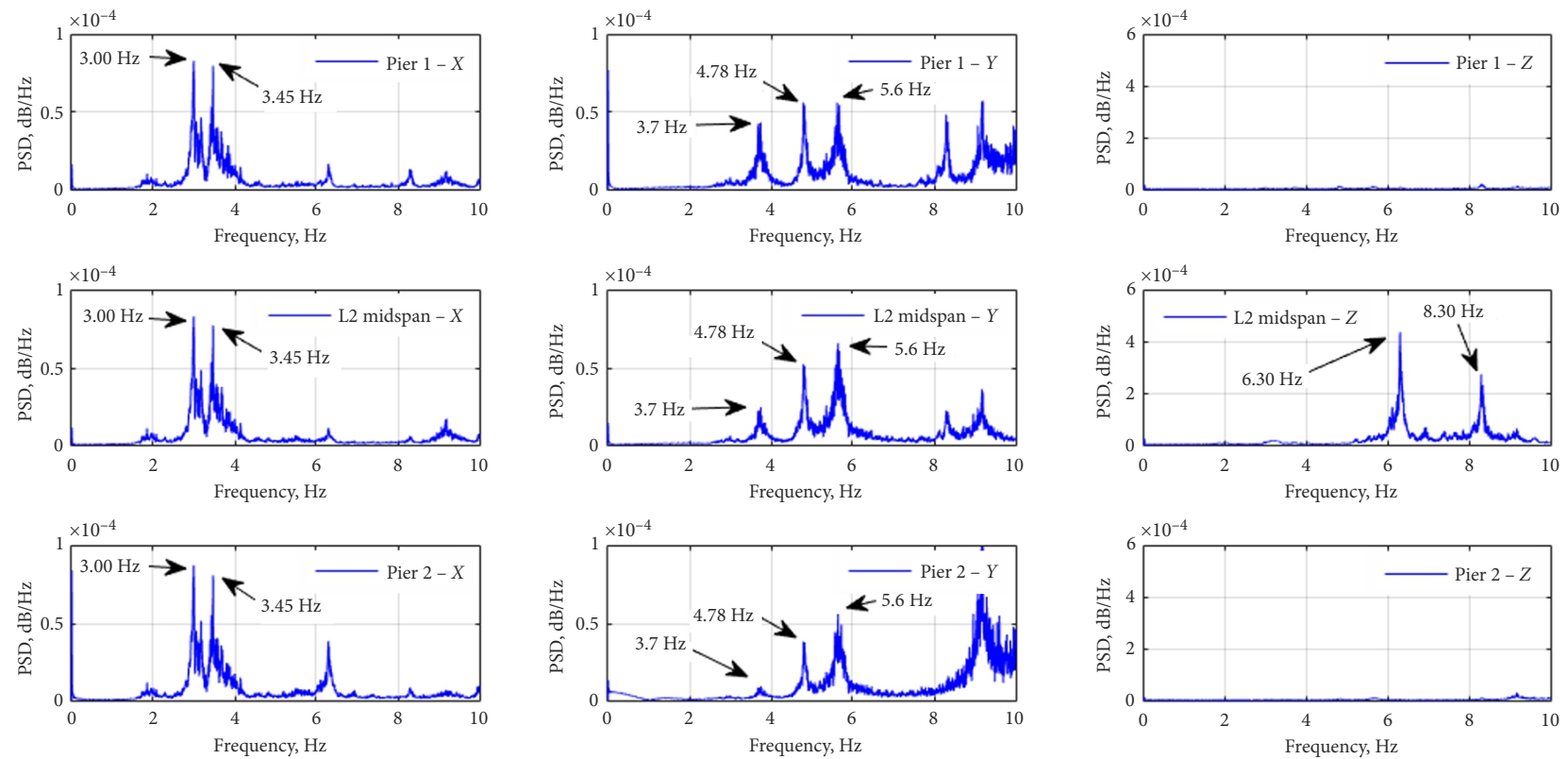

Figure 13. Frequency domain presentation of the signals for the second set of measurements in the second Ambient Vibration Survey
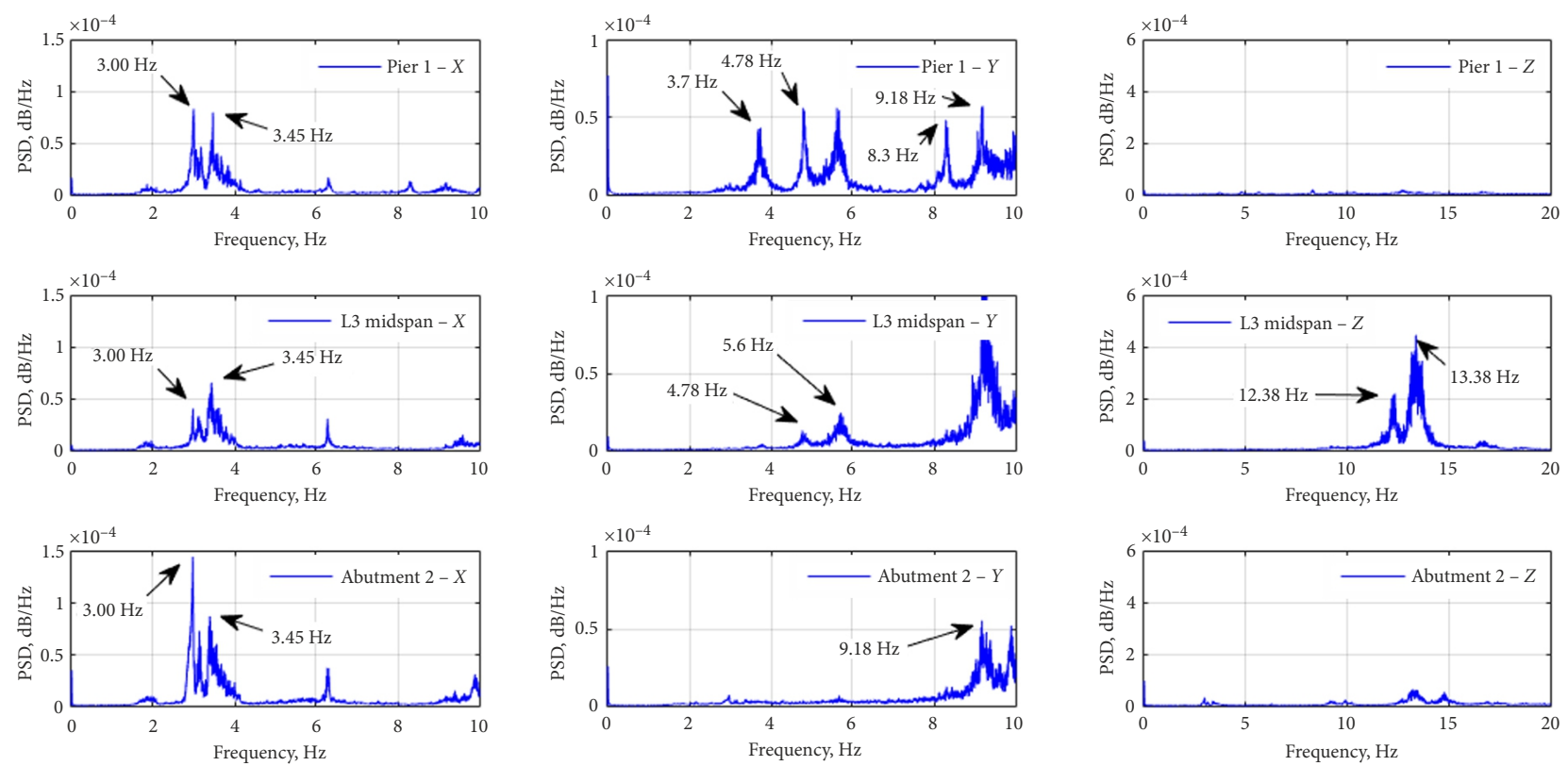

Figure 14. Frequency domain presentation of the signals for the third set of measurements in the second Ambient Vibration Survey

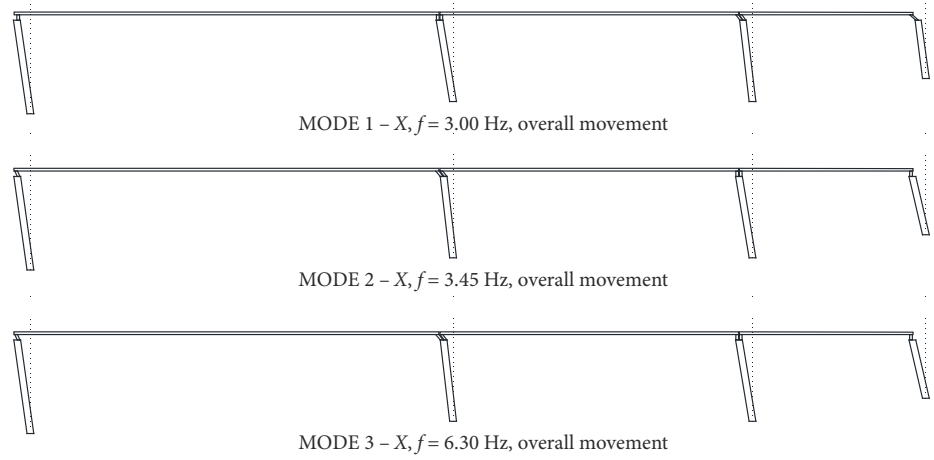

Figure 15. Obtained mode shapes in $X$ direction in the second Ambient Vibration Survey 


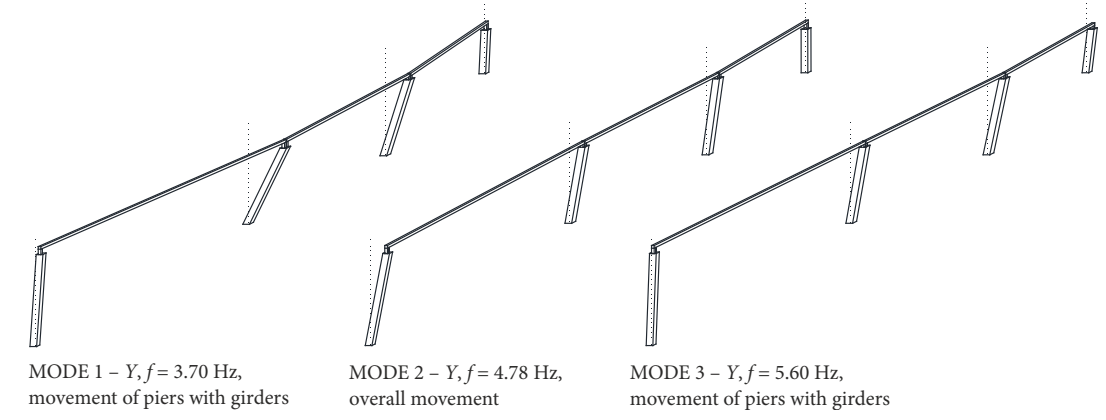

Figure 16. Obtained mode shapes in $Y$ direction in the second Ambient Vibration Survey
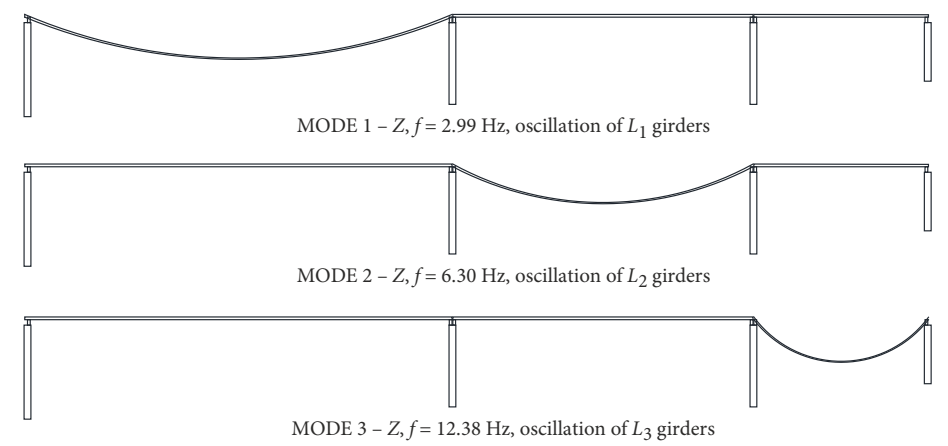

Figure 17. Obtained mode shapes in $Z$ direction in the second Ambient Vibration Survey

Along with $Z$ direction $L_{1}, L_{2}$, and $L_{3}$ oscillate independently. The order of the obtained modal frequencies also reveals their relative length, mass and stiffness values. As expected, the frequency of $L_{2}$ is greater than that of $L_{1}$ and smaller than that of $L_{3}$.

\subsection{Structural behaviour of the completed bridge}

The results of modal testing performed on the second stage represent the dynamic behaviour of the targeted bridge. The obtained mode shapes reveal that, in $X$ and $Y$ direction the dynamic modes are formed by the overall movement of the structure. The cast-in-place reinforced concrete slab is continuous through all length and it causes the girders and the abutments and piers to work all together in $X$ and $Y$ directions.

The dynamic modes in vertical direction seem to be more complicated as compared to the first AVS results since two dominant frequencies appeared. The second dominant frequencies, seen in Figures 12-14, have been investigated in detail. Their existence is dependent on the location of the accelerometer during the second AVS. As it is seen in Figure 11B, the accelerometers have been located on one side of the bridge instead of the middle of it, because of the human traffic. In this condition, the second dominant frequency must represent the rotation of the bridge slab around $X$ axis.

Additionally, an increase in these frequencies (in the $Z$ direction) was also noted. The most important construction work performed between two modal testing is the addition of the cast-in-place reinforced concrete slab. It increases the mass of the bridge deck and contributes to its stiffness. In Eq. (1), where, $f$ is frequency, $m$ is mass and $k$ is stiffness, the frequency of a system is mainly dependent on the mass and stiffness properties. Any increase in the mass of the system results in a decrease in the modal frequencies, while an increase in the stiffness results in an increase in them. Hence, it is concluded that, the stiffness contribution of the cast-in-place reinforced concrete slab is more efficient than its mass increase to alter the vibration frequencies in the vertical direction. Moreover, the cast-in-place slab alters the support conditions of the girders on the abutments and piers. The lack of a mutual frequency trough $L_{1}, L_{2}$, and $L_{3}$ prove that, the continuous beam behaviour does not exist. Hence, it is concluded that, along with the vertical direction, each girder has its own modes and works independently from others.

$$
f=\frac{1}{2 \pi} \sqrt{\frac{k}{m}} .
$$

\subsection{The effects of the performed construction work on the dynamic behaviour}

Comparison of the dynamic properties of the bridge, obtained from two AVSs, reveals the effects of the performed construction works after the first modal testing. The detected differences are interpreted with the performed constructional work as follows:

- as the change in the structural behaviour, three girder beams started to work together in $X$ and $Y$ directions. The main reason of this finding is the cast-in-place reinforced concrete slab, which is continuous through the whole length without a construction joint. 
- in spite of the continuous cast-in-place reinforced concrete slab, three girders still have their own modes in vertical direction $(Z)$.

- the performed construction works, such as the addition of reinforced concrete slab, precast sides and parapets increased the modal frequencies in $X, Y$ and $Z$ directions.

\section{Conclusions}

The performed study has been concluded with the following important findings.

1. The first Ambient Vibration Survey was performed after the placement of the precast bridge girders on the elastomers. The first mode in $X$ direction, second, third and fourth modes in $Y$ directions and first, second and third modes in $Z$ directions proved the individual and separate movement of girders isolated from the piers and abutments. Hence, the elastomers are active to control the dynamic behaviour of the bridge and form a separation line.

2. The second Ambient Vibration Survey was performed after the completion of the construction of the studied bridge. Derived mode shapes in $X$ and $Y$ directions showed the girders of the bridge move altogether. The most effective parameter for altering the dynamic behaviour of the studied bridge between the first and second Ambient Vibration Survey is the cast-in-place reinforced concrete bridge.

3. No mutual frequency was determined for the mode shapes of the girders along with $Z$ direction. For this reason, three bridge spans have their own modes along with the vertical direction.

4. The identified increases in the modal frequencies of the modes in the vertical direction between the first and the second Ambient Vibration Survey, proved that, the stiffness contribution of the cast-in-place reinforced concrete slab is more effective than its mass increase.

\section{Acknowledgments}

This research was supported by the project 214M235, financed by the Scientific and Technological Research Council of Turkey. The author is thankful to the supporter. The help of Tark Tufan during the placement of the accelerometers is also acknowledged.

\section{References}

Altunışık, A. C., Bayraktar, A., Sevim, B., \& Ateş, Ş. (2011). Ambient vibration based seismic evaluation of isolated Gülburnu highway bridge. Soil Dynamics and Earthquake Engineering, 31(11), 1496-1510.

https://doi.org/10.1016/j.soildyn.2011.05.020

Aras, F., \& Altay, G. (2015). Seismic evaluation and structural control of historical Beylerbeyi Palace. Structural Control and Health Monitoring, 22(2), 347-364. https://doi.org/10.1002/stc.1677

Bedon, C., \& Morassi, A. (2014). Dynamic testing and parameter identification of a base-isolated bridge. Engineering Structures, 60, 85-99. https://doi.org/10.1016/j.engstruct.2013.12.017
Benedettini, F., \& Gentile, C. (2011). Operational modal testing and FE model tuning of a cable-stayed bridge. Engineering Structures, 33, 2063-2073.

https://doi.org/10.1016/j.engstruct.2011.02.046

Chan, T. H. T., Law, S. S., \& Yung, T. H. (1998). Modal test on an existing concrete bridge: experience acquired. HKIE Transactions, 5(3), 8-16.

Chisari, C., Bedon, C., \& Amadio, C. (2015). Dynamic and static identification of base-isolated bridges using Genetic Algorithms. Engineering Structures, 102, 80-92.

https://doi.org/10.1016/j.engstruct.2015.07.043

Inman, D. J. (2013). Engineering vibration (720 p.) (4th ed.). Prentice Hall, New Jersey.

Ko, J. M., \& Ni, Y. Q. (2005). Technology developments in structural health monitoring of large-scale bridges. Engineering Structures, 27, 1715-1725.

https://doi.org/10.1016/j.engstruct.2005.02.021

Lin, X., Zhang, L., \& Guo, Q. (2009). Dynamic finite element model updating of prestressed concrete continuous box-girder bridge. Earthquake Engimeering and Engineering Vibrations, 8(3), 399-407. https://doi.org/10.1007/s11803-009-8127-3

Matlab. (2012). The MathWorks, Inc., Natick, Massachusetts, United States.

Min, Z. H., \& Sun, L. M. (2013). Wavelet-based structural modal parameter identification. Structural Control and Health Monitoring, 20, 121-138. https://doi.org/10.1002/stc.474

Michel, C., Gueguen, P., \& Bard, P-Y. (2008). Dynamic parameters of structures extracted from ambient vibration measurements: An aid for the seismic vulnerability assessment of existing buildings in moderate seismic hazard regions. Soil Dynamics and Earthquake Engineering, 28, 593-604. https://doi.org/10.1016/j.soildyn.2007.10.002

Oruç, B., Sarıkaya, A., \& Küçük, Y. E. (2016). Medeniyet University pedestrian overpass detailed design calculation report, Prepared for the Ministry of Transport, Maritime Affairs and Communications.

Osmancikli, G., Bayraktar, A., Turker, T., Ucak, S., \& Mosallam, A. (2015). Finite element model calibration of precast structures using ambient vibrations. Construction and Building Materials, 93, 10-21.

https://doi.org/10.1016/j.conbuildmat.2015.05.096

Paeglite, I., Smirnovs, J., \& Paeglitis, A. (2017). Dynamic behavior of pre-stressed slab bridges. Procedia Engineering, 172, 831-838. https://doi.org/10.1016/j.proeng.2017.02.132

Peeters, B., \& De Roeck, G. (2001). Stochastic system identification for operational modal analysis: a review. Journal of $D y$ namic Systems, Measurement, and Control, 123(12), 659-667. https://doi.org/10.1115/1.1410370

Sanayei, M., Khaloo, A., Gül, M., \& Çatbas, N. F. (2015). Automated finite element model updating of a scale bridge model using measured static and modal test data. Engineering Structures, 102, 66-79.

https://doi.org/10.1016/j.engstruct.2015.07.029

Soyöz, S., Taciroğlu, E., Orakçal, K., Nigbor, R., Skolnik, D., Luş, H., \& Şafak, E. (2013). Ambient and forced vibration testing of a reinforced concrete building before and after its seismic retrofitting. Journal of Structural Engineering, 139, 1741-1752. https://doi.org/10.1061/(ASCE)ST.1943-541X.0000568

Ubertini, F., Gentile, C., \& Materazzi, A. L. (2013). Automated modal dentification in operational conditions and its application to bridges. Engineering Structures, 46, 264-278. https://doi.org/10.1016/j.engstruct.2012.07.031

Zàrate, B. A., \& Caicedo, J. M. (2008). Finite element model updating: multiple alternatives. Engineering Structures, 30, 37242430. https://doi.org/10.1016/j.engstruct.2008.06.012 